\title{
The Rate of Oxygen Absorption of Liquid Iron*
}

\author{
By Takao $\mathrm{CHOH}^{* *}$ and Michio INOUYE**
}

\begin{abstract}
Synopsis
The process of oxygen absorption of liquid iron was studied by taking the formation of iron oxide at the gas-metal interface into account. Experiments on the rate of oxygen absorption were carried out by blowing the $\mathrm{Ar}-\mathrm{O}_{2}$ gas mixtures onto the inductively stirred liquid iron.

It is confirmed that oxygen absorption from the gas phase is represented by a model postulated that most of gaseous oxygen dissolve into liquid iron through the oxide free interface, although some of them form the iron oxide at the interface and then dissolve into liquid iron. The results show that this model is valid for the process of oxygen absorption in the range above 0.057 atm $P_{\mathrm{O}_{2}}$. When the partial pressure of oxygen is lower than 0.057 atm $P_{\mathrm{O}_{2}}$, however, the formation of oxide could practically be neglected, so that the rate of oxygen absorption is controlled simply by the mass transfer in the gas phase.
\end{abstract}

\section{Introduction}

Studies on the reactions between liquid iron and oxidizing gas phase have been noted as the important subjects not only for the scientific interest but also for the steelmaking for a long time. The typical reactions are the decarburization and the oxidization or the oxygen absorption of liquid iron and iron alloys, and in the steelmaking processes these reactions proceed affecting each other. For example, in the processes of the stainless steelmaking by VOD, AOD and ASEA-SKF methods that have developed recently, the mutual relationship between the decarburization reaction and the oxidizing reaction of chromium is adequately utilized. However, although many studies $^{1-15)}$ have been made on the kinetics of oxidization or oxygen absorption of liquid iron and iron alloys under an oxidizing atmosphere, some differences are found in the rate limiting step of those reactions.

In the present work, some fundamental studies on the oxygen absorption of liquid iron have been undertaken in order to determine the rate limiting step and to discuss the mechanism of oxygen absorption comparing with the previous work.

\section{Previous Work}

Previous experimental results which are available in the literature on the reaction of oxygen absorption of liquid iron are classified into two groups according to the oxygen potential in the gas phase and the kind and the concentration of alloying element in liquid iron as follows:

\section{Oxygen Absorption in the Presence of Oxide}

Under the conditions where the oxygen potential in the gas phase and also the concentration of deoxidizing element in liquid iron are high, the oxide layer should be formed at the metal surface as soon as the oxidizing gas is blown on the surface. In this case, oxygen may be absorbed by the dissolution of oxide of iron or alloying element at the interface.

The kinetics of oxidation of liquid iron by pure oxygen was studied by Robertson and Jenkins, ${ }^{1)}$ Lange, ${ }^{2)}$ and Emi et al. ${ }^{3)}$

Emi et al. investigated the oxidation of liquid iron by measuring the pressure change of pure oxygen in a Sieverts type reaction chamber. They found that the rate of oxidation was proportional to the square root of the oxygen pressure and limited by the rate of growth of oxide film, which was formed instantaneously after the introduction of gaseous oxygen into the reaction chamber.

On the other hand, many studies on the oxidation of iron alloy were published. Robertson and Jenkins ${ }^{1)}$ and Baker ${ }^{4}$ observed the formation of oxide film under an oxygen atmosphere for $\mathrm{Fe}-\mathrm{Si}$ alloy and Kaplan and Philbrook ${ }^{5}$ measured the temperature change during the formation of oxide film under an atmosphere of $\mathrm{He}-\mathrm{O}_{2}\left(5 \sim 10 \% \mathrm{O}_{2}\right)$ gas mixture. Ooi and Morishita ${ }^{6}$ also studied the rates of oxidation of $\mathrm{Fe}-\mathrm{Si}, \mathrm{Fe}-\mathrm{Al}$ and $\mathrm{Fe}-\mathrm{Ti}$ alloys under an atmosphere of $\mathrm{Ar}-\mathrm{O}_{2}$ gas mixture by using a Sieverts type reaction chamber, and found that the oxidation was controlled by the diffusion of oxygen in the gas phase. Ito and $\mathrm{Sano}^{\text {7) }}$ investigated the kinetics of oxidation of liquid iron alloys containing deoxidizing elements such as chromium, aluminium, manganese and silicon in a stream of $\mathrm{Ar}-\mathrm{H}_{2} \mathrm{O}$ gas mixture. They showed that the time, when an oxide film appeared at the surface of the melt, decreased with increasing deoxidizing ability of alloying element. Kawai and Mori ${ }^{8)}$ studied the oxidation of liquid $\mathrm{Fe}-\mathrm{Si}(0.5 \sim$ $1 \% \mathrm{Si}$ ) alloys in a stream of $\mathrm{Ar}-\mathrm{H}_{2}-\mathrm{H}_{2} \mathrm{O} \quad(0.027 \sim$ $0.067 \mathrm{~atm} P_{\mathrm{H}_{2} \mathrm{O}}$ ) gas mixture and found that the diffusion of water vapour in the gas phase is the rate limiting step, because the rate is independent of the concentration of silicon in the liquid alloy. Sano and Matsushita $^{9}$ ) also studied the kinetics of oxidation of levitation-melted droplets of $\mathrm{Fe}-\mathrm{Si}(1.22 \sim 1.64 \% \mathrm{Si})$ alloys weighing $0.7 \sim 1.4 \mathrm{~g}$ by blowing $\mathrm{CO}-\mathrm{CO}_{2}$ gas mixture, and concluded that the oxidation of silicon at low partial pressure of carbon dioxide where silicon monoxide might be formed is limited by the mass transfer in the gas phase, while it is controlled by the diffusion of oxygen ions in the oxide layer under high pressure of carbon dioxide and also at lower temperature.

* Originally published in Tetsu-to-Hagané, 65 (1979), 1712, in Japanese. English version received October 8, 1979.

** Faculty of Engineering, Nagoya University, Furo-cho, Chikusa-ku, Nagoya 464. 


\section{Oxygen Absorption without Any Oxide at the Surface}

In most cases of low oxygen potential or low concentration of deoxidizer in liquid iron, a visible oxide film is not formed at the interface until the oxygen concentration in the melt approaches saturation. Under those conditions; therefore, it may be practically unnecessary to consider the formation of oxide at the interface.

Ito and $\mathrm{Sano}^{10)}$ studied the oxygen absorption of liquid iron of 100 to $300 \mathrm{~g}$ contained in a magnesia or zirconia crucible under an atmosphere of $\mathrm{H}_{2} \mathrm{O}-\mathrm{Ar}$ or $\mathrm{H}_{2} \mathrm{O}-\mathrm{H}_{2}-\mathrm{Ar}$ gas mixture, and found that the oxygen absorption below $120 \mathrm{mmHg} P_{\mathrm{H}_{2} \mathrm{O}}$ is limited by the mass transfer process in the gas phase, while, above that pressure, it is controlled by the mass transfer in the liquid phase. $\mathrm{Vig}$ and $\mathrm{Lu}^{11}$ investigated the rates of oxygen absorption of levitated iron droplets in a stream of $\mathrm{N}_{2}-\mathrm{O}_{2}$ or $\mathrm{Ar}-\mathrm{O}_{2}$ gas mixture and suggested that those rates below $10 \% \mathrm{O}_{2}$ were controlled by the mass transfer process in the gas phase and those above $10 \% \mathrm{O}_{2}$ were controlled by the mass transfer in the liquid phase or the chemical reaction at the interface. They also showed that, at higher temperatures, those rates decreased due to a remarkable vapourization of liquid iron. Similar experimental studies in a stream of $\mathrm{He}-10 \mathrm{ppm} \mathrm{O}_{2}$ gas mixture and the oxygen absorption of free falling liquid iron droplets in the air were also made by Greenberg and McLean. ${ }^{12)}$ They found that those rates were limited by the mass transfer in the gas phase. Previously, on the other hand, the present authors investigated the rates of oxygen absorption of liquid iron from $\mathrm{O}_{2}-\mathrm{Ar}$, $\mathrm{O}_{2}-\mathrm{N}_{2}, \mathrm{CO}_{2}-\mathrm{Ar}, \mathrm{CO}_{2}-\mathrm{N}_{2}$ and $\mathrm{H}_{2} \mathrm{O}-\mathrm{N}_{2}$ gas mixtures and suggested that the rate controlling step depends on the partial pressure of oxygen. ${ }^{13-15)}$ However, there are some disagreements in the conclusions between these works and the previous other works.

\section{Experimental Apparatus and Procedure}

A vacuum induction furnace of $35 \mathrm{KVA}$ was used in this study similary to the previous works. ${ }^{13,14)}$ Electrolytic iron of $400 \mathrm{~g}$ was melted in a magnesia crucible ( $\mathrm{MgO} 98 \%, \mathrm{CaO} 1 \%$, inner dia. $38 \mathrm{~mm}$ ) under an atmosphere of argon, and deoxidized with small amounts of iron carbon alloy in vacuo. After these treatments, argon was introduced to the furnace and the melt was maintained at $1600^{\circ} \mathrm{C}$. Then $\mathrm{O}_{2}-$ $\operatorname{Ar}\left(0.1 \sim 100 \% \mathrm{O}_{2}\right)$ gas mixtures were passed onto the melt surface through a nozzle set at the position 15 $\mathrm{mm}$ above the melt surface at a flow rate of $1 \sim 5$ $l / \mathrm{min}$ and the samples for analysis were taken with a silica tube at any time intervals. Carbon and oxygen contents were determined by the coulometric method. Temperature was measured by an optical pyrometer through a prism.

\section{Kinetics of Oxygen Absorption of Liquid Iron}

1. Effects of Oxygen Partial Pressure and Gas Flow Rate on the Rate of Oxygen Absorption of Liquid Iron

Typical experimental results on the rates of oxygen absorption of liquid iron from $\mathrm{O}_{2}-\mathrm{Ar}(3,40,60$ and $80 \% \mathrm{O}_{2}$ ) gas mixtures are shown in Figs. 1 to 4 . It is seen from these figures that those rates increase with increasing oxygen partial pressure and increasing gas flow rate. Furthermore it is found that those rates at the concentrations above $40 \% \mathrm{O}_{2}$ decrease with increasing oxygen concentration in the melt as shown in Figs. 2 to 4 , although the rate at $3 \% \mathrm{O}_{2}$ is practically independent of the oxygen concentration in the range studied. On the other hand, it is observed that the rate of oxygen absorption during initial $15 \mathrm{sec}$ is low when the gas mixture of $80 \% \mathrm{O}_{2}-\mathrm{Ar}$ is introduced at a lower flow rate as shown in Fig. 4. This is probably because the gas phase at the interface is insufficiently substituted by the reaction gas just after the start of experiment.

Solid lines in Figs. 2 to 4 will be interpreted later. The rates of oxygen absorption were generally obtained from the initial slopes of the experimental results independent of the solid lines. In the case of the insufficient substitution of the gas phase at the initial stage, those rates were obtained from the slope at $15 \mathrm{sec}$ after the start of experiment. The rates are plotted against the partial pressure of oxygen on a logarithmic scale as shown in Fig. 5. It is clearly observed that the rates of oxygen absorption are practically proportional to the oxygen partial pressure in the most range and increase with increasing gas flow rate. However, those rates deviate gradually from this proportional relationship in the range of high oxygen partial pressures. Previously the present authors considered that this deviation arises from the change of the rate limiting step from the mass transfer in the gas phase to the mass transfer in the liquid phase. However, considering the experimental results that those rates in this range increase with increasing gas flow rate as shown in Fig. 5, the previous model seems to be inadequate. Accordingly, it seems reasonable to consider that, even at a higher oxygen pressure and also at a higher gas flow rate, the oxide coverage should be restricted to the surface just beneath the gas nozzle where the rate of oxygen absorption is independent of the condition of the gas phase. Therefore, the oxide free interface still remains. Consequently, the oxygen absorption of liquid iron should proceed through these two different interfaces and it becomes gradually independent of the change in the condition of gas phase as the oxide coverage increases.

It is also found that the rates of oxygen absorption are apt to decrease when the partial pressure of oxygen becomes lower than $1 \%$ and also the gas flow rate decreases. In this range, the rates of oxygen absorption are apparently proportional to $3 / 2$ power of the oxygen partial pressure as shown previously. ${ }^{13}$ ) However, they increase with increasing gas flow rate and most of them become to be proportional to the oxygen partial pressure. Therefore, it is unreasonable to consider the chemical reaction as a rate limiting step of oxygen absorption in this range. Here, it is assumed that some of oxygen molecules are caught by the evaporated iron atoms and then a part of them leaves the system. This probability may increase 


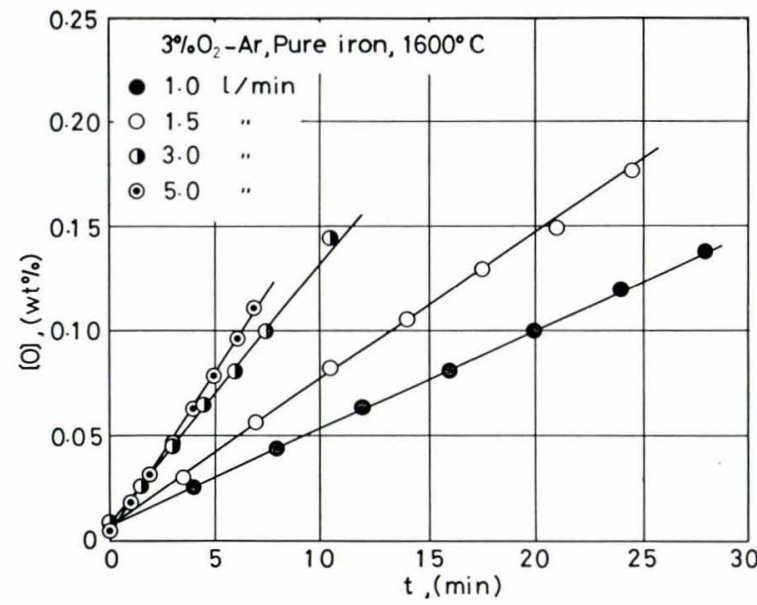

Fig. 1. Effect of gas flow rate on the rate of oxygen absorption of liquid iron at $1600^{\circ} \mathrm{C} . \quad\left(3 \% \mathrm{O}_{2}-\mathrm{Ar}\right)$

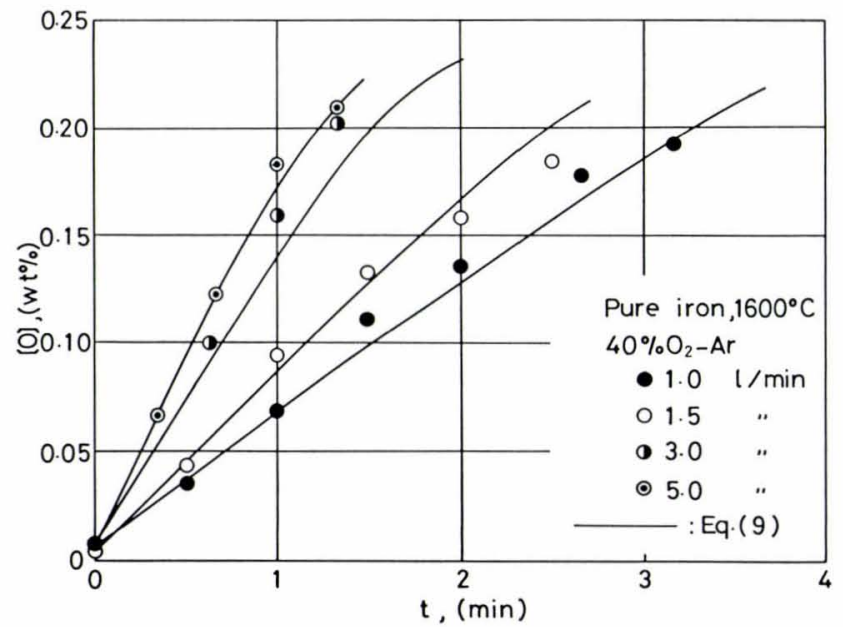

Fig. 2. Effect of gas flow rate on the rate of oxygen absorption of liquid iron at $1600^{\circ} \mathrm{C}$. Curves are represented by Eq. (9). $\left(40 \% \mathrm{O}_{2}-\mathrm{Ar}\right)$

with increasing thickness of gaseous boundary layer, in other words, if the gas flow rate is slow, the rate of oxygen absorption decreases and the deviation from the linear relationship becomes larger as shown in Fig. 5. According to the experimental results obtained by the authors ${ }^{16)}$ on the effect of residual pressure of argon in a reaction tube on the rate of evaporation of liquid iron, the rate of evaporation of liquid iron becomes $0.0065 \mathrm{mg} /\left(\mathrm{cm}^{2} \cdot \mathrm{sec}\right)$ which was obtained by extrapolating the residual pressure to $1 \mathrm{~atm}$ $P_{\text {Ar }}$. This value corresponds to $7.5 \times 10^{-5} \mathrm{~mol} / \mathrm{min}$ for the interfacial area under the present experimental condition. On the other hand, for a gas mixture of $0.1 \% \mathrm{O}_{2}-\mathrm{Ar}$ at a gas flow rate of $1 \mathrm{l} / \mathrm{min}$, the rate of mass transfer of oxygen in the gas phase becomes $8.9 \times 10^{-5} \mathrm{~g}$-atom $/ \mathrm{min}$. In this condition, assuming that all of the evaporated iron atoms catch oxygen molecules and form $\mathrm{FeO}$ as an oxide in the gas phase, it is estimated that $90 \%$ of oxygen molecules supplied from the gas phase should be consumed by the iron vapour and leave the system, as the maximum value. However, the experimental results suggest that the efficiency of oxygen absorption from the gas phase reaches $29 \%$ that is higher than that estimated from

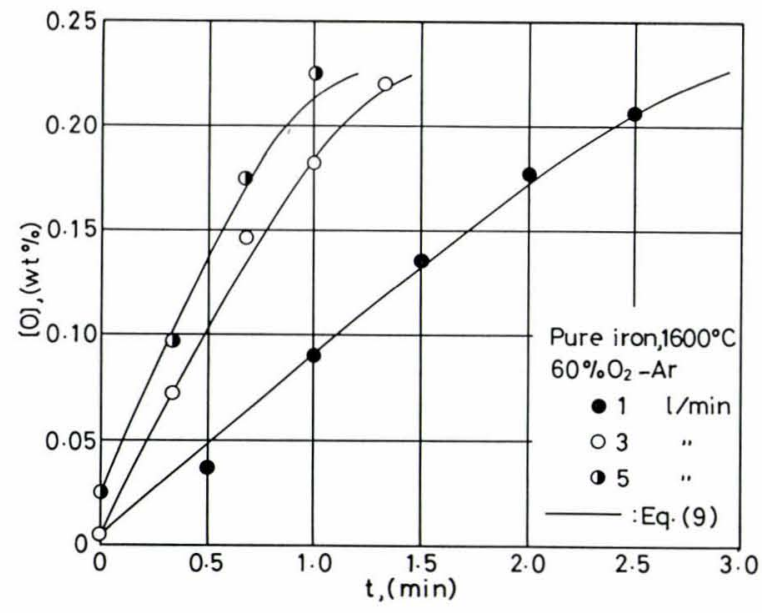

Fig. 3. Effect of gas flow rate on the rate of oxygen absorption of liquid iron at $1600^{\circ} \mathrm{C}$. Curves are represented by Eq. (9). $\quad\left(60 \% \mathrm{O}_{2}-\mathrm{Ar}\right)$

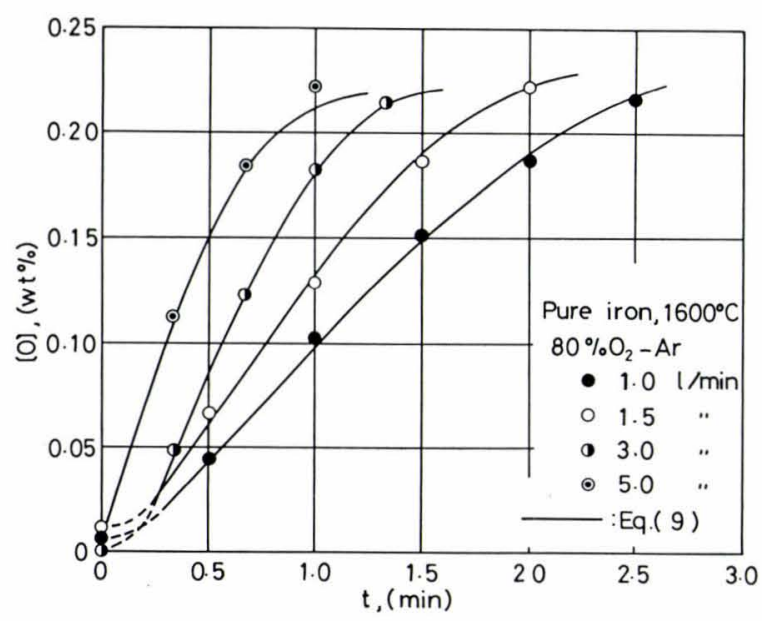

Fig. 4. Effect of gas flow rate on the rate of oxygen absorption of liquid iron at $1600^{\circ} \mathrm{C}$. Curves are represented by Eq. (9). $\quad\left(80 \% \mathrm{O}_{2}-\mathrm{Ar}\right)$

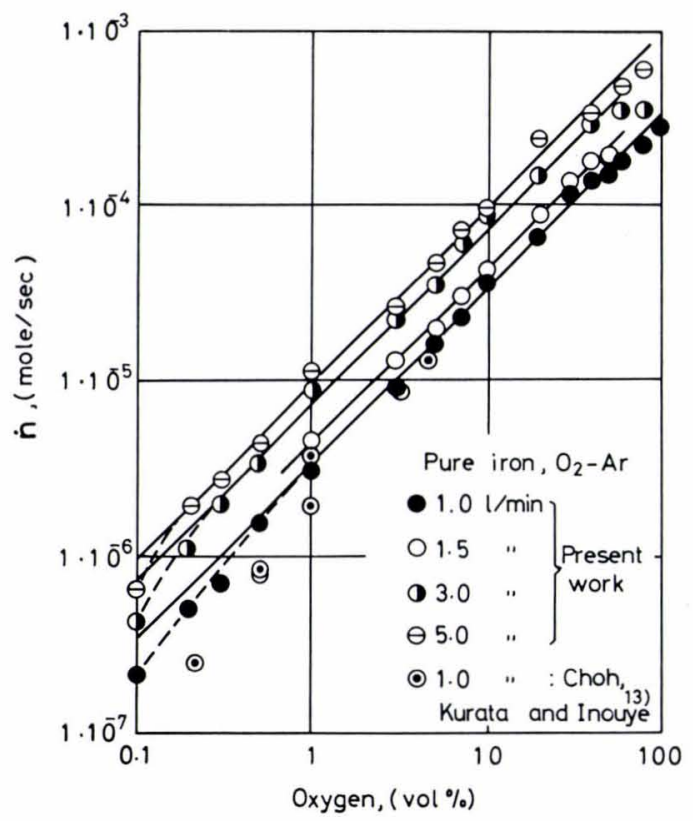

Fig. 5. Effects of gas flow rate and oxygen partial pressure on the rate of oxygen absorption of liquid iron at $1600^{\circ} \mathrm{G}$. 
the calculated results mentioned above. It is probably because the thickness of the gas boundary layer under a gas flow rate of $1 \mathrm{l} / \mathrm{min}$ decreases, although the rate of evaporation of liquid iron may increase by the increase of gas flow rate. On the other hand, when the oxygen concentration and the flow rate of gas increase, for example, $0.2 \% \mathrm{O}_{2}$ and $5 \mathrm{l} / \mathrm{min}$, the rate of mass transfer of oxygen in the gas phase becomes $8.9 \times 10^{-4} \mathrm{~g}$-atom $/ \mathrm{min}$, such an effect of evaporation of liquid iron decreases relatively and the rate of oxygen absorption becomes to be proportional to the oxygen partial pressure.

\section{Effects of Sulphur and Molybdenum Shield on the Rate of Oxygen Absorption of Liquid Iron}

The rates of oxygen absorption of liquid iron containing $0.08 \sim 0.14 \% \mathrm{~S}$ were measured at a gas flow rate of $1 \mathrm{l} / \mathrm{min}$ or $1.5 \mathrm{l} / \mathrm{min}$ as shown in Fig. 6. It is found that those rates agree with those free from sulphur as described by the solid lines in Fig. 6. Namely it is probable that sulphur has no effect on the oxygen absorption of liquid iron. On the other hand, the rate of oxygen absorption was studied for liquid iron under a decreasing effect of inductive stirring by inserting one or two sheets of molybdenum susceptor of $0.2 \mathrm{~mm}$ thickness between the crucible and the protective crucible and the results obtained are also shown in Fig. 6. It is also found that those rates agree well with those for unshielded melt shown by the solid lines, and the effect of the molybdenum shield seems to be negligible for the oxygen absorption of liquid iron. This is probably due to the fluid flow by the Marangoni effect occurred just after the start of the experiment as already described by Barton and Brimacombe $^{17)}$ who have investigated the rate of oxygen absorption of molten copper. In the present work, it was also confirmed by the observed result that the

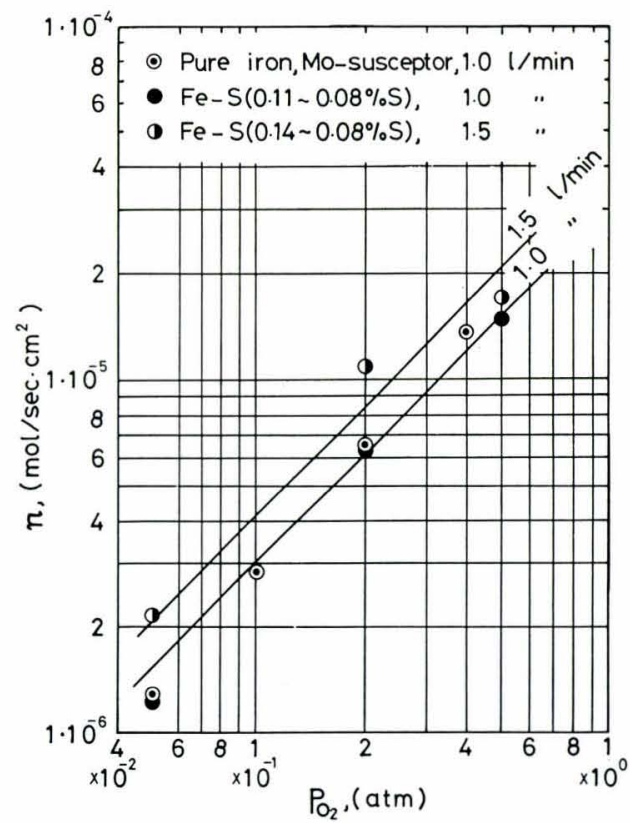

Fig. 6. Effect of sulphur addition and molybdenum susceptor on the rate of oxygen absorption of liquid iron at $1600^{\circ} \mathrm{C}$. quiet surface of liquid iron shielded by the molybdenum susceptor in an argon atmosphere began to flow strongly after introducing gaseous oxygen. Secondary, it is probable that the contribution of the resistance of mass transfer in the liquid phase to the oxygen absorption under the present experimental condition is practically negligible compared with those of other resistances. Those contributions will be discussed in the next section.

\section{Mechanisms of Oxygen Absorption of Liquid Iron}

Considering the rate limiting step from the experimental results shown in Fig. 5, it is generally accepted that the initial rate of oxygen absorption of liquid iron may be controlled by the mass transfer in the gas phase. However, some of the rates of oxygen absorption decrease with increasing oxygen concentration in the melt as shown in Figs. 2 to 4 . Then, assuming that the mass transfer in liquid iron is the rate controlling step of oxygen absorption, the rate equation (1) was applied to the present experimental results.

$$
\ln \left[\left(C_{s}-C_{0}\right) /\left(C_{s}-C\right)\right]=\left(F_{1} / V\right) k_{l} t
$$

However, since the linear relationships between $\ln \left[\left(C_{s}-C_{0}\right) /\left(C_{s}-C\right)\right]$ and $\left(F_{1} / V\right) \cdot t$ of Eq. (1) were not established for all results, the rate of oxygen absorption of liquid iron can not be represented by Eq. (1).

According to the observation of the melt surface during oxygen absorption, it was often found that an oxide phase of liquid iron was formed continuously beneath the nozzle even at a lower oxygen concentration below the saturated concentration in liquid iron, and then flowed towards the perimeter of the melt, and almost disappeared before arriving at the crucible wall by the dissolusion into liquid iron. Therefore, the oxygen partial pressure at the gas-metal interface under the present experimental condition may change along the radial distance, although an oxide phase should be formed above $8 \times 10^{-9} \mathrm{~atm} P_{\mathrm{O}_{2}}{ }^{18)}$ at $1600^{\circ} \mathrm{C}$. The blowing gas just beneath the axis of nozzle should have the same oxygen partial pressure as the gas introduced. However, when the gas flows on the interface towards the perimeter of the melt, the interfacial oxygen partial pressure may decrease with increasing flowing distance because oxygen at the interface is consumed by forming an oxide phase. Therefore, outside of the oxide forming region, the interfacial pressure must reach below the equilibrium value of $8 \times 10^{-9} \mathrm{~atm} P_{\mathrm{O}_{2}}$. Consequently, it is probable that the oxygen pressure at the interface should be a function of the position. Furthermore, considering that the area occupied by the oxide depends on the oxygen concentration in liquid iron, the interfacial oxygen partial pressure becomes also a function of the reaction time.

On the other hand, the reaction of oxygen absorption under a condition where an oxide phase occupies a part of the interface may proceed through the following two parallel processes. At the interface covered by the oxide film, oxygen in the gas phase formes the oxide film and then transfer into liquid iron 
through the process of dissolution of oxide, while at the residual part of the interface that is free from oxide, oxygen in the gas phase dissolves directly into liquid iron. In the present work, however, in order to simplify the mechanism, a simple model for the oxygen absorption was suggested by taking the approximate value of the interfacial oxygen partial pressure.

Now, it is assumed that the rate of mass transfer in the gas phase $\dot{n}_{g}$ is represented by

$$
\dot{n}_{g}=F_{1} k_{g}\left[P_{\mathrm{O}_{2}}-\left(\overline{P_{\mathrm{O}_{2} i}}\right)_{\mathrm{I}}\right]
$$

where $\left(\overline{P_{\mathrm{O}_{2} i}}\right)_{\mathrm{I}}$ is the mean oxygen partial pressure for the entire gas-liquid interface containing the oxide film region. Moreover, the rate of mass transfer in the liquid phase for the oxygen absorption through the oxide free interface is shown by Eq. (3).

$$
\dot{n}_{l}=F_{2} k_{0}\left(\bar{n}_{e}-n\right)
$$

In this case, the mean value of $\bar{n}_{e}$ is adopted, although the interfacial oxygen concentration should be in equilibrium with the interfacial oxygen partial pressure and should be a function of the position.

On the other hand, assuming that the oxide is formed by the chemisorption of oxygen atoms and the bonding with iron atoms at the interface, the rate of reaction may be defined by Eq. (4) which is similar to the relationship applied already by Emi et al. to the rate of oxidation of liquid iron under the condition of the chemical reaction control.

$$
\dot{n}_{r}=\left(F_{1}-F_{2}\right) k_{r}\left(\overline{P_{\mathrm{O}_{2}}}\right)_{1 \mathrm{II}}^{1 / 2}
$$

where $\left(\overline{P_{\mathrm{O}_{2}} i}\right)_{\mathrm{II}}$ indicates the mean oxygen partial pressure at the gas-oxide interface. In a steady state, the relationship of Eq. (5) can be established among Eqs. (2) to (4).

$$
2 \dot{n}_{g}=\dot{n}_{l}+2 \dot{n}_{r}
$$

On the other hand, the change of oxygen concentration in the bulk of the melt or the rate of oxygen absorption obtained in the present work is written

$$
\frac{d c}{d} d t=\frac{F_{2}}{V} k_{0}\left(\bar{C}_{e}-C\right)+\frac{F_{1}-F_{2}}{V} k_{l}\left(C_{s}-C\right) \ldots \ldots \ldots
$$

where, the first term in the right hand side represents the rate of oxygen absorption through the oxide free interface, and the second term represents the rate of oxygen absorption by the dissolution of oxide formed at the interface. Then the first term in Eq. (6) is further described by the first and the second terms of Eq. (7) derived from Eqs. (2) to (5). Consequently Eq. (6) becomes Eq. (7). From the second and the third terms in Eq. (7), the amount of oxygen accumulated at the gas-liquid interface as an oxide film can be estimated.

$$
\begin{aligned}
\frac{d c}{d t}= & \frac{F_{1}}{V}\left[\frac{100 M_{\mathrm{O}_{2}}}{\rho} \cdot k_{g}\left\{P_{\mathrm{O}_{2}}-\left(\overline{P_{\mathrm{O}_{2}}}\right)_{\mathrm{I}}\right\}\right. \\
& \left.-\alpha \frac{100 M_{\mathrm{O}_{2}}}{\rho} \cdot k_{r}\left(\overline{\mathrm{P}_{\mathrm{O}_{2}}}\right)_{\mathrm{II}}^{1 / 2}+\alpha k_{l}\left(C_{s}-C\right)\right]
\end{aligned}
$$

$$
\alpha=\left(F_{1}-F_{2}\right) / F_{1}
$$

where, $\alpha$ indicates the fraction of sites occupied by oxide film.

Here, in order to analyze the process of oxygen absorption, it is important how to approximate the mean values of interfacial oxygen partial pressures $\left(P_{\mathrm{O}_{2} i}\right)_{\mathrm{I}}$ and $\left(\overline{P_{\mathrm{O}_{2} i}}\right)_{\mathrm{II}}$ in Eq. (7). In the present work, assuming that the interfacial oxygen partial pressure beneath the axis of nozzle corresponds to the oxygen pressure in the gas introduced, and also the oxygen pressure at the edge of oxide film becomes nearly zero, the value of $\left(P_{\mathrm{O}_{2} i}\right)_{\mathrm{II}}$ is approximated by the relationship $\left(P_{\mathrm{O}_{2} i}\right)_{\mathrm{II}}=(1 / 2) P_{\mathrm{O}_{2}}$. As for the interfacial oxygen partial pressures $\left(P_{\mathrm{O}_{2} i}\right)_{\mathrm{I}}$, the relationship $\left(P_{\mathrm{O}_{2} i}\right)_{\mathrm{I}}=$ $(1 / 2) \alpha P_{\mathrm{O}_{2}}$ is assumed by multiplying $\alpha$ in order that $\left(\overline{P_{\mathrm{O}_{2} i}}\right)_{\mathrm{I}}$ becomes zero when the entire gas-liquid interface is free from the oxide at a low oxygen partial pressure. Now, substituting this relationship into Eq. (7) and taking $\alpha$ as zero, such a relationship as shown in Fig. 5 that the initial rate of oxygen absorption is proportional to the oxygen partial pressure, can be obtained. By the approximation as mentioned above, Eq. (7) becomes to Eq. (9).

$$
\begin{aligned}
\frac{d c}{d t}= & \frac{F_{1}}{V}\left[\frac{100 M_{\mathrm{O}_{2}}}{\rho} \cdot k_{g} P_{\mathrm{O}_{2}}\left(1-\frac{\alpha}{2}\right)\right. \\
& -\alpha\left\{\frac{\left.\left.100 M_{\mathrm{O}_{2}} \cdot k_{r}\left(\frac{P_{\mathrm{O}_{2}}}{2}\right)^{1 / 2}-k_{l}\left(C_{s}-C\right)\right\}\right]}{\rho}\right.
\end{aligned}
$$

However, Eq. (9) is valid above 0.057 atm $P_{\mathrm{O}_{2}}$ which corresponds to the condition that the numerical value in the braces \{\} of Eq. (9) is positive; when the oxygen pressure is lower than the above value, $\alpha$ should be taken as zero.

Now, in order to express the value of $\alpha$ in terms of the rate of mass transfer in the gas phase and the oxygen concentration in the melt, Eq. (10) is obtained by integrating Eq. (9) under the initial condition $C=C_{\mathbf{0}}$ assuming that the value of $\alpha$ is constant.

$$
\frac{1}{\beta} \ln \frac{\gamma+\beta\left(C_{s}-C_{0}\right)}{\gamma+\beta\left(C_{s}-C\right)}=\frac{F_{1}}{V} t
$$

where $\beta$ and $\gamma$ are represented by Eqs. (11) and (12), respectively.

$$
\begin{aligned}
& \beta=\alpha k_{l} \\
& \gamma=\frac{100 M_{\mathrm{O}_{2}}}{\rho}\left\{k_{g} P_{\mathrm{O}_{2}}\left(1-\frac{\alpha}{2}\right)-\alpha k_{r}\left(P_{\mathrm{O}_{2}} / 2\right)^{1 / 2}\right\}
\end{aligned}
$$

Then, $\alpha$ is determined by the trial-and-error method so that the experimental results could be expressed by Eq. (10), using the following physical properties.

(a) $k_{g}$ : The values of $k_{g}$ were estimated from the lines in Fig. 5, assuming that the initial rates of oxygen absorption in the range of oxygen partial pressure between 0.01 and $0.3 \mathrm{~atm}$ are limited by the mass transfer in the gas phase, since those rates are proportional to the oxygen pressure as shown in Fig. 5: $1 \mathrm{l} / \mathrm{min}: 3.00 \times 10^{-5}, 1.5 \mathrm{l} / \mathrm{min}: 4.14 \times 10^{-5}, 3.0 \mathrm{l} / \mathrm{min}$ : $7.32 \times 10^{-5}, \quad 5.0 \mathrm{l} / \mathrm{min}: \quad 9.08 \times 10^{-5} \mathrm{~mol} \cdot \mathrm{cm}^{-2} \cdot \mathrm{sec}^{-1}$. $\mathrm{atm}^{-1}$.

(b) $k_{l}: k_{l}=0.028 \mathrm{~cm} \cdot \mathrm{sec}^{-1}$ which was obtained 
by substituting $k_{\mathrm{N}}=0.05 \mathrm{~cm} / \mathrm{sec}^{19)} \quad D_{\mathrm{o}}=2.9 \times 10^{-5}$ $\mathrm{cm}^{2} / \mathrm{sec}^{20)}$ and $D_{\mathrm{N}}=9.2 \times 10^{-5} \mathrm{~cm}^{2} / \mathrm{sec}^{21)}$ into the relationship $k_{l}=k_{\mathrm{N}}\left(D_{\mathrm{O}} / D_{\mathrm{N}}\right)^{1 / 2}$, assuming that $k_{l}$ is represented by the penetration theory.

(c) $k_{r}: k_{r}=8.03 \times 10^{-5} \mathrm{~mol} /\left(\mathrm{cm}^{2} \cdot \mathrm{sec} \cdot \mathrm{atm}^{1 / 2}\right)$ that was deduced from $k_{r}=1.8 \mathrm{STP} \mathrm{cm}^{3} /\left(\mathrm{cm}^{2} \cdot \mathrm{sec} \cdot \mathrm{atm}^{1 / 2}\right)^{3)}$ obtained at 1 atm $P_{\mathrm{O}_{2}}$.

(d) $\rho: \rho=7 \mathrm{~g} / \mathrm{cm}^{3}$ that is a mean value of several values reported in the literature.

Now, taking the experimental results of $30 \% \mathrm{O}_{2}-$ Ar at a gas flow rate of $1 / / \mathrm{min}$, the values of $1 / \alpha$ are obtained from Eq. (10), and are plotted against the oxygen concentration in liquid iron. A linear relationship is obtained as shown in Fig. 7 and is represented by Eq. (13).

$$
\alpha=0.00653 /(0.281-C)
$$

According to Eq. (13), the value of $\alpha$ increases with increasing oxygen concentration in liquid iron. Here, the relationship $0.281=1.22 C_{s}$ is assumed when $C_{s}$ is the saturated oxygen concentration $\left(C_{s}=0.23 \%\right.$ at $\left.1600^{\circ} \mathrm{C}\right)$.

On the other hand, it is probable that, when the oxygen concentrations in the melt are the same, the value of $\alpha$ increases with increasing rate of mass transfer of oxygen in the gas phase. Assuming that the value of $\alpha$ is proportional to the rate of mass transfer in the gas phase $\dot{n}_{g}$, a numerator of Eq. (13) is also modified as $0.00653=k F_{1} k_{g} P_{\mathrm{O}_{2}}$ when the reverse direction in Eq. (2) is neglected for the sake of simplification. Now, substituting the values of $k_{g}$ and $P_{\mathrm{O}_{2}}$ which were used already for the determination of $\alpha$ in Fig. 7, the relationship $k F_{1}=725$ can be obtained and Eq. (13) becomes

$$
\alpha=725 k_{g} P_{\mathrm{O}_{2}} /\left(1.22 C_{s}-C\right)
$$

This is also valid for the oxygen absorption of high chromium iron alloys which will be shown in the next paper. For all cases, however, the condition $\alpha \leq 1$ should be imposed.

Since the volume of liquid iron decreases gradually during the experiment owing to the sampling, the volume of liquid metal is represented by Eq. (15)

$$
V=V_{0}-a \cdot t
$$

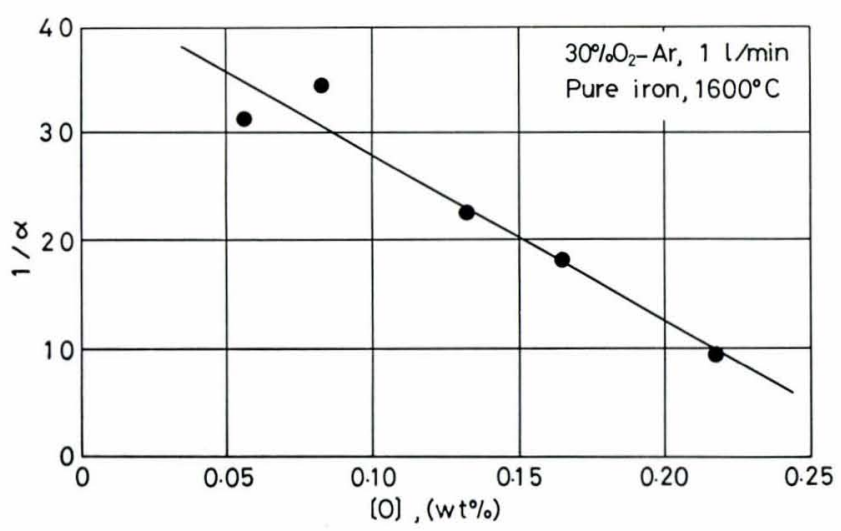

Fig. 7. Relationship between oxygen concentration and $1 / \alpha$. where the value of $a$ is the mean sampling weight per second estimated from the division of total sampling weight by the reaction time.

Now, substituting Eqs. (14) and (15) into Eq. (9), the rate of oxygen absorption can be calculated by the Runge Kutta method and is shown by the solid lines in Figs. 2 to 4 . It is clearly observed that the calculated results agree well with the experimental points. Accordingly, the present model postulating that, some of gaseous oxygen molecules form an oxide film at the interface and then dissolve into liquid iron and the rest dissolves into liquid iron through the oxide free interface, seems to be established.

The amount of oxygen accumulated at the interface as an oxide film, $\Delta \mathrm{O}_{\mathrm{ox}}$, can be also calculated by integrating the second and the third terms in Eq. (9) under the assumption that the oxygen concentration in the melt is constant for a very short period of time. The calculated results are plotted against the ratio of oxygen concentration to the saturated one in Fig. 8. It is clear from Fig. 8 that the value of $\Delta \mathrm{O}_{\mathrm{ox}}$ increases with increasing oxygen partial pressure and increasing oxygen concentration in the melt. It is also found that the value of $\Delta \mathrm{O}_{\mathrm{ox}}$ is apparently independent of the gas flow rate. This is because both the rate of oxygen absorption and the rate of oxide formation or the values of $C / C_{s}$ and $\Delta \mathrm{O}_{\text {ox }}$ increase with increasing gas flow rate. However, if the values of $\Delta \mathrm{O}_{\mathrm{ox}}$ are plotted against the reaction time, it is recognized that those values increase with increasing gas flow rate.

Furthermore, let us consider the behaviours of oxide at the surface and dissolved oxygen. Under the same assumption that the oxygen concentration is constant for a short period of time as in the foregoing calculation of $\Delta \mathrm{O}_{\mathrm{ox}}$, the amount of oxygen supplied from the gas phase and that of oxygen absorption by the dissolution of oxide, $\underline{\mathrm{O}}_{d}$, can be calculated from the first

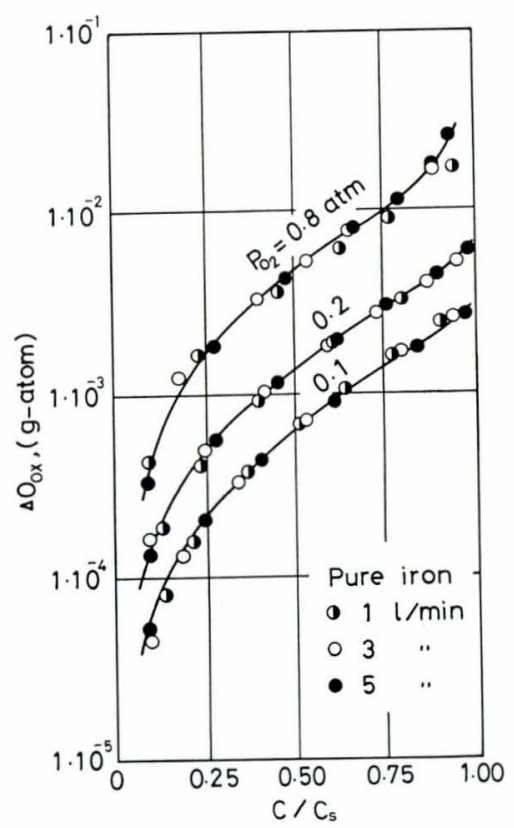

Fig. 8. Relationship between the amount of oxygen accumulated at the gas-metal interface as the oxide phase and $C / C_{s}$. 
and the third terms of Eq. (9) individually. By using the value of $\Delta \mathrm{O}_{\mathrm{ox}}$, the amount of oxygen absorption through the oxide free interface, $\underline{\mathrm{O}}_{f}$, can also be estimated. When the oxygen partial pressures are 0.1 and $0.8 \mathrm{~atm}$ and the gas flow rate is $5 \mathrm{l} / \mathrm{min}$, the calculated results of those values are plotted against the time as shown in Figs. 9 and 10. It is found from Fig. 9 that, at lower oxygen partial pressures such as $0.1 \mathrm{~atm}$, both the values of $\Delta \mathrm{O}_{\mathrm{ox}}$ and $\underline{\mathrm{O}}_{d}$ are small compared with that of $\underline{\mathrm{O}}_{f}$; namely, most of oxygen molecules should dissolve into liquid iron through the oxide free interface. If the oxygen partial pressure becomes high such as $0.8 \mathrm{~atm}$, it is also confirmed from Fig. 10 that, although most of oxygen molecules dissolve through the oxide free interface even at higher oxygen pressures as in Fig. 9, the value of $\Delta \mathrm{O}_{o x}$ is about ten times larger than at $0.1 \mathrm{~atm} P_{\mathrm{O}_{2}}$. Here, the rate of oxygen absorption containing oxygen accumulated in oxide film decreases somewhat with increasing reaction time, and the absorption efficiency of oxygen decreases. This is probably because the oxide film in which oxygen is once accumulated impedes the direct contact between gaseous oxygen and liquid iron, and moreover the rate of dissolution of the oxide into liquid iron is extremely low as compared with the rate of oxygen absorption through the oxide free interface.

On the other hand, if the ratio of the maximum rate of mass transfer in the gas phase and that of oxide formation, $r_{v}=k_{g} P_{\mathrm{O}_{2}} /\left(k_{r} P_{\mathrm{O}_{2}}^{1 / 2}\right)$ is considered, it becomes $r_{v}=0.4$ for the gas flow rate of $1 l / \mathrm{min}$, and $r_{v}=1.1$ for $5 \mathrm{l} / \mathrm{min}$ when the oxygen partial pressure is $1 \mathrm{~atm}$ $P_{\mathrm{O}_{2}}$.

Those results suggest that the mass transfer in the gas phase may play an important role for the oxygen absorption and also the oxidation of liquid iron, even under the condition where the most of the gas-liquid interface is covered with an oxide film. Consequently it is reasonable to consider that the oxygen absorption in liquid iron may mainly be controlled by the mass transfer in the gas phase at any oxygen partial pressure and at any gas flow rate.

\section{Conclusions}

The rates of oxygen absorption of liquid iron under an atmosphere of $\mathrm{O}_{2}-\mathrm{Ar}$ gas mixture at $1 \mathrm{~atm}$ were investigated and the following results were obtained.

(1) At lower oxygen concentrations in liquid iron, the initial rate of oxygen absorption increases with increasing gas flow rate or oxygen partial pressure, and it is probable that it is mainly controlled by the mass transfer in the gas phase. At oxygen partial pressures below $0.057 \mathrm{~atm}$, the mass transfer in the gas phase controls the rate of oxygen absorption even in the range of high oxygen concentration in liquid iron.

(2) In the range of oxygen partial pressure above $0.057 \mathrm{~atm}$, the process of oxygen absorption of liquid iron is represented by a model postulated that the most of gaseous oxygen molecules should dissolve into liquid iron through the oxide free interface, although some of them form the iron oxide at the interface and then dissolve into liquid iron. In this case, it is confirmed that the amount of oxygen accumulated as an oxide film at the interface increases with increasing gas flow rate, oxygen partial pressure and oxygen concentration in liquid iron.

(3) Considering the results obtained by the estimation of the amounts of accumulated oxygen at the interface, absorbed oxygen through the oxide free interface and also absorbed oxygen by the dissolution of oxide, it is concluded that the most of absorbed oxygen are those through the oxide free interface and the rate of oxide dissolution is low compared with the rate of oxide formation.

\section{Nomenclature}

$a$ : Volume of sample taken per unit time $\left(\mathrm{cm}^{3} \cdot \mathrm{sec}^{-1}\right)$

$C$ : Concentration of oxygen in melt (\%)

$C_{0}$ : Initial concentration of oxygen in melt (\%)

$C_{s}$ : Concentration of oxygen being in equilibrium with the oxide $(\%)$

$\overline{C_{e}}$ : Mean concentration of oxygen being in equilibrium with the gas phase $(\%)$

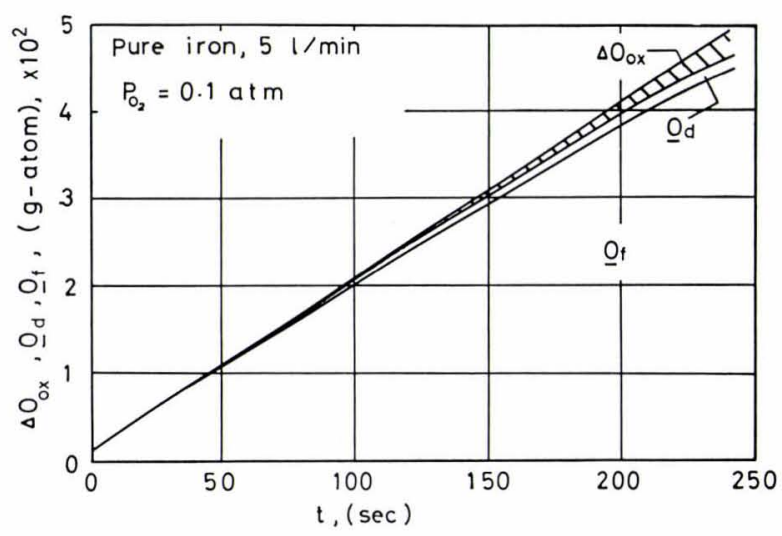

Fig. 9. Behaviours of oxygen accumulated at the gas-metal interface $\Delta \mathrm{O}_{\mathrm{ox}}$, oxygen absorbed by the dissolution of oxide $\underline{\mathrm{O}}_{d}$ and oxygen absorbed through the oxide free gas-metal interface $\underline{\mathrm{O}}_{f}$. $\left(5 \mathrm{l} / \mathrm{min}, P_{\mathrm{O}_{2}}=0.1\right.$ atm)

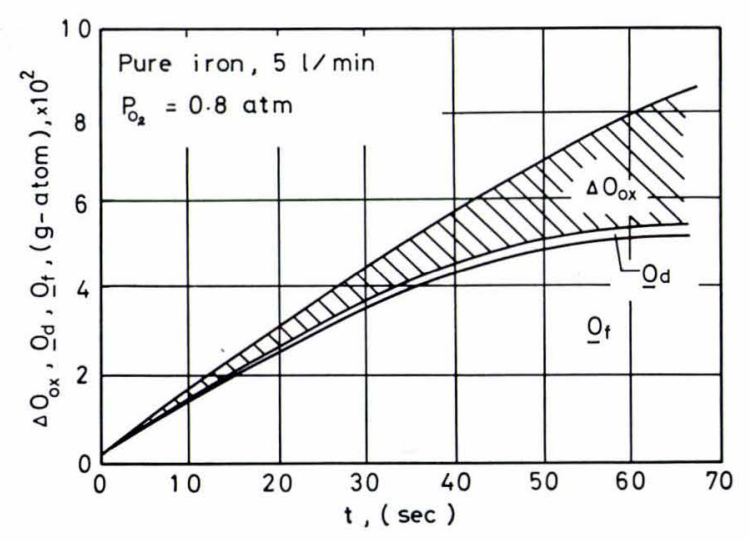

Fig. 10. Behaviours of oxygen accumulated at the gasmetal interface $\Delta \mathrm{O}_{o x}$, oxygen absorbed by the dissolution of oxide $\underline{\mathrm{Q}}_{d}$ and oxygen absorbed through the oxide free gas-metal interface $\underline{\mathrm{O}}_{f} . \quad(5 \mathrm{l} / \mathrm{min}$, $\left.P_{\mathrm{O}_{2}}=0.8 \mathrm{~atm}\right)$ 
$D_{\mathrm{N}}, D_{\mathrm{O}}$ : Diffusivities of nitrogen and oxygen in liquid iron $\left(\mathrm{cm}^{2} \cdot \mathrm{sec}^{-1}\right)$

$F_{1}, F_{2}$ : Areas of the entire interface and the oxide free interface $\left(\mathrm{cm}^{2}\right)$

$j$ : Rate of oxygen absorption $\left(\mathrm{mol} \cdot \mathrm{cm}^{-2}\right.$. $\sec ^{-1}$ )

$k$ : Proportional constant $\left(\% \cdot \mathrm{sec} \cdot \mathrm{mol}^{-1}\right)$

$k_{0}$ : Over-all mass transfer coefficient of oxygen absorption through the oxide free interface $\left(\mathrm{cm} \cdot \mathrm{sec}^{-1}\right)$

$k_{g}$ : Mass transfer coefficient in the gas phase $\left(\mathrm{mol} \cdot \mathrm{sec}^{-1} \cdot \mathrm{cm}^{-2} \cdot \mathrm{atm}^{-1}\right)$

$k_{l}$ : Mass transfer coefficient in the liquid phase $\left(\mathrm{cm} \cdot \mathrm{sec}^{-1}\right)$

$k_{\mathrm{N}}$ : Mass transfer coefficient of nitrogen absorption $\left(\mathrm{cm} \cdot \mathrm{sec}^{-1}\right)$

$k_{r}$ : Rate constant of chemical reaction (mol. $\mathrm{sec}^{-1} \cdot \mathrm{cm}^{-2} \cdot \mathrm{atm}^{-1 / 2}$ )

$M_{\mathrm{O}_{2}}$ : Molecular weight of gaseous oxygen ( $\mathrm{g}$. $\mathrm{mol}^{-1}$ )

$n$ : Concentration of oxygen $\left(\mathrm{g}\right.$-atom $\left.\cdot \mathrm{cm}^{-3}\right)$

$\bar{n}_{e}$ : Mean concentration of oxygen being in equilibrium with the gas phase (g-atom. $\mathrm{cm}^{-3}$ )

$\dot{n}:$ Rate of oxygen absorption $\left(\mathrm{mol} \cdot \mathrm{sec}^{-1}\right)$

$\dot{n}_{g}$ : Rate of mass transfer in the gas phase $\left(\mathrm{mol} \cdot \mathrm{sec}^{-1}\right)$

$\dot{n}_{l}$ : Rate of mass transfer in the liquid phase $\left(\mathrm{mol} \cdot \mathrm{sec}^{-1}\right)$

$\dot{n}_{r}:$ Rate of oxide formation $\left(\mathrm{mol} \cdot \mathrm{sec}^{-1}\right.$ )

$\underline{\mathrm{O}}_{d}$ : Amount of oxygen absorbed by the dissolution of oxide (g-atom)

$\underline{\mathrm{O}}_{f}$ : Amount of oxygen absorbed through the oxide free interface (g-atom)

$\Delta \mathrm{O}_{\mathrm{ox}}$ : Amount of oxygen accumulated at the interface as an oxide (g-atom)

$P_{\mathrm{O}_{2}}:$ Oxygen partial pressure (atm)

$P_{\mathrm{O}_{2} i}$ : Interfacial oxygen partial pressure (atm)

$\left(\overline{P_{\mathrm{O}_{2} i}}\right)_{\mathrm{I}}:$ Mean interfacial oxygen partial pressure of entire interface (atm)

$\left(\overline{P_{\mathrm{O}_{2}}}\right)_{\mathrm{II}}$ : Mean interfacial oxygen partial pressure in the oxide region (atm)

$r_{v}$ : Ratio of the maximum rate of mass transfer in the gas phase to that of chemical reac-

\author{
tion $(-)$ \\ $t$ : Time (sec) \\ $V:$ Volume of liquid iron $\left(\mathrm{cm}^{3}\right)$ \\ $V_{0}$ : Initial volume of the liquid iron $\left(\mathrm{cm}^{3}\right)$ \\ $\alpha$ : Fractional occupancy of the interface by the \\ oxide film (-) \\ $\beta: \quad$ Eq. (11) $\left(\mathrm{cm} \cdot \mathrm{sec}^{-1}\right)$ \\ $\gamma:$ Eq. (12) $\left(\% \cdot \mathrm{cm} \cdot \mathrm{sec}^{-1}\right)$ \\ $\rho$ : Density of liquid iron $\left(\mathrm{g} \cdot \mathrm{cm}^{-3}\right)$
}

\section{REFERENCES}

1) D.G.C. Robertson and A. E. Jenkins: Heterogeneous Kinetics at Elevated Temperatures, Plenum Press, New York, (1970), 393.

2) W. Lange: Z. Metallk., 30 (1938), 274.

3) T. Emi, W. D. Boorstein and R. D. Pehlke: Met. Trans., 5 (1974), 1959

4) R. Baker: JISI, 205 (1967), 637.

5) R. S. Kaplan and W. O. Philbrook: Trans. AIME, 245 (1969), 2195.

6) H. Ooi and M. Morishita: Kawasaki Steel Technical Report, 2 (1970), 14

7) K. Ito and K. Sano: Tetsu-to-Hagané, 51 (1965), 1252.

8) Y. Kawai and K. Mori: Tetsu-to-Haganê, 56 (1970), 695.

9) N. Sano and Y. Matsushita: Trans. ISIJ, 11 (1971), 232.

10) K. Ito and K. Sano: Tetsu-to-Hagané, 49 (1963), 1652.

11) S. K. Vig and W-K. Lu: JISI, 209 (1971), 630.

12) L. A. Greenberg and A. McLean: Trans. ISIJ, 14 (1974), 395.

13) T. Choh, M. Kurata and M. Inouye: Proceedings ICSTIS, I, Suppl. Trans. ISIJ, 11 (1971), 548.

14) T. Choh, F. Kuze and M. Inouye: Tetsu-to-Hagané, 59 (1973), 373

15) T. Choh and M. Inouye: Tetsu-to-Hagané, 59 (1973), 387.

16) K. Ieda, T. Choh and M. Inouye: Tetsu-to-Hagané, 61 (1975), S84.

17) R. G. Barton and J. K. Brimacombe: Met. Trans,, 8B (1977), 417.

18) Basic Open Hearth Steelmaking, ed. by W. O. Philbrook, M. B. Bever, H. E. Emerick and B. M. Larsen, AIME, New York, (1951), 573.

19) T. Choh and M. Inouye: Tetsu-to-Hagané, 53 (1967), 1393.

20) K. Suzuki and K. Mori: Tetsu-to-Hagané, 57 (1971), 2219.

21) M. Inouye, Y. Kojima, T. Choh, S. Uekewa and Y. Yamada: Tetsu-to-Hagané, 59 (1973), 205. 